\title{
Frailty Significantly Associated with a Risk for Mid-term Outcomes in Elderly Chronic Coronary Syndrome Patients: a Prospective Study
}

Caglar Ozmen1', MD; Ali Deniz¹, MD; İmam Günay¹, MD; İlker Ünal², PhD; Aziz Inan Celik², MD; Çağlar Emre Çağlıyan ${ }^{1}$, MD; Onur Sinan Deveci ${ }^{1}$, MD; Mesut Demir ${ }^{1}$, MD; Mehmet Kanadaşı ${ }^{1}$, MD; Ayhan Usal ${ }^{1}$, MD

DOI: 10.21470/1678-9741-2019-0484

\begin{abstract}
Introduction: Frailty is a condition of elderly characterized by increased vulnerability to stressful events. Frail patients are more likely to have adverse events. The purposes of this study were to define frailty in patients aged $\geq 70$ years with chronic coronary syndrome (CCS) and to evaluate mortality and prognostic significance of frailty in these patients.

Methods: We included 99 patients, $\geq 70$ years old (mean age $74 \pm 5.3$ years), with diagnosis of CCS. They were followed-up for up to 12 months. The frailty score was evaluated according to the Canadian Study of Health and Aging (CSHA). All patients were divided as frail or non-frail. The groups were compared for their characteristics and clinical outcomes.

Results: Fifty patients were classified as frail, and 49 patients as non-frail. The 12-month Major Adverse Cardiac Events (MACE)
\end{abstract}

rate was $69.4 \%$ in frail patients and $20 \%$ in non-frail patients. Frailty increases the risk for MACE as much as 3.48 times. Two patients died in the non-frail group and 11 patients died in the frail group. Frailty increases the risk for death as much as 6.05 times. When we compared the aforementioned risk factors by multivariate analysis, higher CSHA frailty score was associated with increased MACE and death (relative risk [RR] $=22.94,95 \%$ confidence interval $[\mathrm{Cl}] 3.33-158.19, P=0.001$, for $\mathrm{MACE} ; \mathrm{RR}=\mathbf{7 . 4 1}$, 95\% Cl 1.44-38.03, $P=0.016$, for death).

Conclusion: Being a frail elderly CCS patient is associated with worse outcomes. Therefore, frailty score should be evaluated for elderly CCS patients as a prognostic marker.

Keywords: Frailty. Frail Elderly. Risk Factors. Confidence Intervals. Multivariate Analysis. Prognosis. Canada. Aging. Death. Heart.

\section{Abbreviations, acronyms \& symbols}

\begin{tabular}{lllll}
\hline ACEI & $=$ Angiotensin-converting enzyme inhibitor & CVD & $=$ Cardiovascular diseases \\
ACS & $=$ Acute coronary syndrome & $\mathrm{EF}$ & $=$ Ejection fraction \\
ARB & $=$ Angiotensin II receptor blockers & $\mathrm{Hb}$ & $=$ Hemoglobin \\
ASA & $=$ Acetylsalicylic acid & $\mathrm{HbA} 1 \mathrm{C}$ & $=$ Glycated hemoglobin \\
BMI & $=$ Body mass index & $\mathrm{HDL}$ & $=$ High-density lipoprotein \\
BNP & $=$ B-type natriuretic peptide & $\mathrm{HR}$ & $=$ Hazard ratio \\
Ca & $=$ Calcium & $\mathrm{K}$ & $=$ Potassium \\
CABG & $=$ Coronary artery bypass grafting & $\mathrm{LDL}$ & $=$ Low-density lipoprotein \\
CAD & $=$ Coronary artery disease & $\mathrm{MACE}$ & $=$ Major Adverse Cardiac Events \\
CCS & $=$ Chronic coronary syndromes & $\mathrm{Mg}$ & $=$ Magnesium \\
CI & $=$ Confidence interval & $\mathrm{MI}$ & $=$ Myocardial infarction \\
COPD & $=$ Chronic obstructive pulmonary disease & $\mathrm{Na}$ & $=$ Sodium \\
CRP & $=$ C-reactive protein & $\mathrm{PCl}$ & $=$ Percutaneous coronary intervention \\
CSHA & $=$ Canadian Study of Health and Aging & $\mathrm{RR}$ & $=$ Relative risks \\
\end{tabular}

'Department of Cardiology, Faculty of Medicine, Cukurova University, Adana, Turkey. ${ }^{2}$ Department of Biostatistics, Faculty of Medicine, Cukurova University, Adana, Turkey. ${ }^{3}$ Department of Cardiology, Gebze Fatih State Hospital, Kocaeli, Turkey.

This study was carried out at the Department of Cardiology, Faculty of Medicine, Cukurova University, Adana, Turkey.
Correspondence Address:

Caglar Ozmen

(ID) https://orcid.org/0000-0002-7285-991X

Department of Cardiology, Cukurova University Faculty of Medicine Balcali Hospital, 01330, Sarıcam, Adana, Turkey.

Email: caglarozm@hotmail.com 


\section{INTRODUCTION}

Cardiovascular diseases (CVD) are the number one cause of death in the world ${ }^{[1]}$. With a prolonged life expectancy and the development of interventional treatment for these diseases, new problems, such as geriatric syndromes, are evolving. Several studies have reported the mortality rate of Major Adverse Cardiac Events (MACE) between the ages of $60-80$ years and $>80$ years as $4.1 \%$ and $11.5 \%$, respectively, which is far higher than of people $<$ 60 years old, who have a $1 \%$ mortality rate ${ }^{[2,3]}$.

Frailty is a physiological decline of bodily functions that can occur in every organ system. It is determined by old age and is associated with comorbidities and disabilities ${ }^{[2]}$. Frail patients with coronary artery disease (CAD) are more likely to experience adverse events than non-frail people ${ }^{[4]}$. In elderly CAD patients, a longer life expectancy has led to a greater focus on improving the patients' ability to function and their quality of life ${ }^{[5]}$. As a result, the concept of frailty has attracted increasing attention as a mean of identifying patients more prone to poor outcomes in coronary events ${ }^{[6]}$.

Although the pathways leading to frailty and CAD are involved, they both have been strongly associated with chronic low-grade inflammation ${ }^{[7]}$. Chronic inflammation results in the oxidation of lipoproteins and the activation of atheromatous plaques $^{[8]}$. As frailty involves multisystem physiologic dysregulation, it is conceivable that chronic inflammation contributes to frailty through its detrimental effects on other physiologic organ systems, such as the musculoskeletal and endocrine systems, anemia, and clinical and subclinical $C A D^{[9,10]}$. In addition to sharing causal pathways, CAD can contribute to the development of frailty ${ }^{[11]}$.

Less is known about frailty and chronic coronary syndromes (CCS); and frailty is rarely used in the assessment of cardiovascular treatment and prognosis. Frailty reflects biological rather than chronological age, and this may explain why there is significant heterogeneity in clinical outcomes in the elderly patient population. The purposes of this study were to define frailty in patients aged $\geq 70$ years with CCS and to evaluate the mortality and prognostic significance of frailty in these patients.

\section{METHODS}

This prospective study was conducted in accordance with the Declaration of Helsinki and the Good Clinical Practice Guidelines. Our study was approved by the local ethics committee issued by the University of Cukurova, number 90/15. All patients enrolled in the study signed written informed consent. Between January 2018 and August 2018, we prospectively enrolled 99 consecutive patients, aged $\geq 70$ years, with diagnosis of CCS, and who underwent elective coronary angiography with or without percutaneous coronary intervention ( $\mathrm{PCl}$ ) at Cukurova University Hospital, Cardiology Department. The exclusion criteria were as follows: (1) if the patient was not willing to participate; (2) if the patient was diagnosed with acute coronary syndrome (ACS).

This is a prospective study addressing a Canadian Study of Health and Aging (CSHA) frailty scoring system that, to the best of our knowledge, has not been used previously to predict the risk of mid-term outcomes for CCS patients. The clinical and laboratory data and echocardiography were collected and recorded. The patients were divided into two groups, frail and non-frail patients, according to the CSHA frailty scoring system. The frailty scores of the patients were also evaluated by this system ${ }^{[12]}$. The CSHA frailty scale is a seven-point scale that determines frailty scores with a good prognostic value, depending on clinical judgment. The patients are frail if the score is $\geq 5$.

The impact of comorbidities on risk of CAD was quantified by a CAD-specific index ${ }^{[13]}$. In this scoring system, each separate significant comorbidity (hypertension, current smoker, history of a cerebrovascular event, chronic obstructive pulmonary disease, metastatic tumor, renal disease, peripheral vascular disease, tumor, and diabetes mellitus with complications) has a coefficient, and the final score is calculated by the sum of the factors. The patients are at a low to moderate risk if the score is $0-3$ and at high risk if it is $\geq 4$.

$\mathrm{PCl}$ was performed according to the physicians' decision and preference depending on the patients' clinical and angiographic statuses. The severity and the burden of coronary atherosclerosis were determined based on the Gensini score ${ }^{[14]}$. This score is associated with short- and long-term cardiovascular risk and considers artery morphology, coronary anatomy, and the severity of stenosis in lesions. Patients with Gensini scores $\geq 20$ were defined as having equivalent to severe $C A D$, which meant they had approximately $70 \%$ or more stenosis lesions in the proximal left anterior descending artery ${ }^{[15]}$. All the scoring systems were evaluated by two cardiologists separately, and the final scores were recorded upon agreement.

Patients were followed-up for up to 12 months after the study. The patients without admission during the study's followup period were called on the phone, and the relevant data were gathered by telephone interviews. The primary outcome was all-cause mortality. The secondary outcomes were composite of death, stroke/transient ischemic attack, major bleeding, and recurrent cardiovascular events during the12-month followup. The clinical data, history of hospitalization, major bleeding, myocardial infarction (MI), stroke, and death were recorded during each visit or during hospitalization. Bleeding was considered major if at least one of the following was present: blood transfusion, intracranial or retroperitoneal bleeding, a hemoglobin decrease of $>3 \mathrm{~g} / \mathrm{dL}$ with definite cause, or a hemoglobin decrease of $>4 \mathrm{~g} / \mathrm{dL}$ without apparent source ${ }^{[16]}$. Stroke and transient ischemic attack were defined according to a consensus statement ${ }^{[17]}$.

\section{Statistical Analysis}

For each continuous variable, normality was checked by Kolmogorov-Smirnov and Shapiro-Wilk tests and by histograms. Comparisons between groups were applied using the Student's t-test for normally distributed data, and the Mann-Whitney $U$ test was used for the data not normally distributed. All the categorical variables were analyzed by Pearson's chi-squared test or Fisher's exact test, as appropriate. Logistic regression was used to determine the risk factors for the presence of MACE and mortality. The data were presented at different survival rates of both the frail and non-frail patients and the Gensini low/high 
score patients, which were described in the Kaplan-Meier curve using the log-rank test. The Kappa statistic was used to analyze the correlation between the patients' frailty status (absent/ present), CAD-specific index (high/low), and Gensini score (high/low). Cox regression was used to calculate hazard ratios (HR) for MACE and death. The IBM SPSS Statistics Version 20.0 package program was used for the statistical analysis of the data. The results were presented as relative risks (RR) and their 95\% confidence intervals $(\mathrm{Cl})$, as mean \pm standard deviation and as $\mathrm{n}$ (\%). A $P$-value $<0.05$ was considered significant.

\section{RESULTS}

We included 99 consecutive patients, aged $\geq 70$ years, and diagnosed with CCS. The mean follow-up time was $10 \pm 2$ months. Their mean age was $74 \pm 5.3$ years. Among them, 64 (64.7\%) were between 70-79 years old and 35 (35.3\%) were older ( $\geq 80$ years). Fifty patients (50.5\%) were classified as frail and 49 patients (49.5\%) were non-frail. Fifty-five patients (55.6\%) encountered at least one outcome (major bleeding, Ml, stroke, re-hospitalization, or death) and 13 patients (13.1\%) died during the follow-up period. Regarding comorbidity, six patients had malignancy, and two of them died during the follow-up period. In our study, 22 patients were revascularized. Of these patients, 19 (86.4\%) had a primary outcome event, but none died within the first month of inclusion. Six (27.2\%) of these 22 patients died during the 12-month follow-up.

When comparing frail and non-frail patients, determined as such according to the CSHA, the groups were similar with respect to age, diabetes mellitus, chronic renal disease, anemia, distribution of gender, body mass index, blood pressure, heart rate, laboratory data (except for calcium), and low-density lipoprotein (LDL) levels (Table 1). Calcium and LDL levels were found to be higher in frail patients (calcium level: $9.0 \pm 0.9 \mathrm{mg} /$ $\mathrm{dL}$ in frails, $8.3 \pm 1.9$ in non-frails, $P=0.045$; LDL level: $137.0 \pm 48.0$ $\mathrm{mg} / \mathrm{dl}$ in frails, $106.5 \pm 32.2$ in non-frails, $P<0.001)$. There were lower uses of angiotensin-converting enzyme inhibitors and angiotensin receptor blockers (50.0\% vs. 77.6\%, $P=0.006)$ and higher uses of acetylsalicylic acid ( $86 \%$ vs. $67.3 \%, P=0.034)$ in frail patients compared to non-frail patients. Ejection fraction (EF) values were similar between the groups (EF: $56.2 \pm 10.0 \%$ in non-frails, $53.0 \pm 12.4 \%$ in frails, $P=0.114$ ). Frail patients presented a greater burden of comorbidities, including higher rates of a $\mathrm{PCl}$ history and malignancy $(38.0 \%$ vs. $12.2 \%$ for $\mathrm{PCl}$ history; $12.0 \%$ vs. $0 \%$ for malignancy, $P=0.005$ and $P=0.027$, respectively). Revascularization ratio ( $\mathrm{PCl}$ or coronary artery bypass grafting) was found to be higher in frail patients (38\% in frails, $6.1 \%$ in non-frails, $P<0.001)$. They also had a higher CAD-specific index score and Gensini score (10.2 \pm 2.7 vs. 2.95 $\pm 2.1, P=0.027$ for CADspecific index score; $71.42 \pm 21$ vs. 23.73 $\pm 13, P<0.001$ for Gensini score) (Table 1).

Within the follow-up period, 13 patients (13.1\%) died. Two patients $(4.1 \%)$ in the non-frail group died (including two sudden deaths and one MI) and 11 patients (22.0\%) died in the frail group (including two sudden deaths, two worsening heart failures, two neoplasms, two lung infections, and multiple organ failures). Patients who died also had high frailty score and Gensini score (frailty score: $5.5 \pm 1.3$ vs. 4.4 $\pm 1.7, P=0.026$; Gensini score: $74.9 \pm 35.9$ vs. $43.7 \pm 37.2, P=0.006)$. There were significantly more smoking habits found in the group with deaths (61.5\% vs. 26.7\%, $P=0.021$ ). The albumin levels were found to be significantly lower in both the group with deaths and MACE (3.3 $\pm 0.6 \mathrm{vs}$. $3.7 \pm 0.5 \mathrm{gr} / \mathrm{dl}, P=0.014$, for MACE; and $3.1 \pm 0.7 \mathrm{vs}$. $3.7 \pm 0.5 \mathrm{gr} / \mathrm{dl}$, $P=0.014$, for death) (Table 2). Figure 1 shows the Kaplan-Meier survival estimates according to frailty status. In our study, the 12-month survival rate was $77 \%$ in frail patients and $93 \%$ in nonfrail patients. Frailty was independently associated with a risk for death by multiple regression analyses ( $R R=7.41,95 \% \mathrm{Cl} 1.44-$ 38.03, $P=0.016)$. The effect of frailty on death can be seen based on the crude HR, which was 6.05 (95\% Cl 1.34-27.31). In our study, the 12 -month survival rate was $97.3 \%$ in low-moderate CADspecific index patients and $80.6 \%$ in high CAD-specific index patients. The 12 -month survival rate was $95.7 \%$ in patients with a low Gensini score and $79.2 \%$ in patients with a high Gensini score.

The overall MACE incidence was 55.6\%. In our study, the 12-month MACE rate was $69.4 \%$ in frail patients and $20 \%$ in non-frail patients. The MACE incidence included 13 deaths,

Table 1. Comparison of the the baseline characteristics.

\begin{tabular}{l|c|c|c}
\hline & Non-frail patients (n=49) & Frail patients (n=50) & P-value \\
\hline Gender (\%) (male) & 63.3 & 72.0 & 0.395 \\
\hline Age (year) & $74.7 \pm 7.6$ & $77.8 \pm 9.4$ & 0.071 \\
\hline Hypertension (\%) & 67.3 & 74.0 & 0.513 \\
\hline Diabetes mellitus (\%) & 32.7 & 48.0 & 0.153 \\
\hline Current smoking (\%) & 28.6 & 34.0 & 0.560 \\
\hline CABG history (\%) & 14.3 & 20.0 & 0.451 \\
\hline COPD (\%) & 18.4 & 16.0 & 0.795 \\
\hline Chronic renal disease (\%) & 6.1 & 4.0 & 0.678 \\
\hline
\end{tabular}




\begin{tabular}{|c|c|c|c|}
\hline Stroke history (\%) & 10.2 & 8.0 & 0.741 \\
\hline $\mathrm{PCl}$ history (\%) & 12.2 & 38.0 & 0.005 \\
\hline Dementia (\%) & 10.2 & 14.0 & 0.563 \\
\hline Peptic ulcer (\%) & 20.4 & 10.0 & 0.171 \\
\hline Anemia (\%) & 22.4 & 14.0 & 0.276 \\
\hline Osteoporosis (\%) & 20.4 & 16.0 & 0.570 \\
\hline Married/single (\%) & $85.7 / 14.3$ & $92.0 / 8.0$ & 0.357 \\
\hline Malignancy history (\%) & 0 & 12.0 & 0.027 \\
\hline $\mathrm{BMI}\left(\mathrm{kg} / \mathrm{m}^{2}\right)$ & $28.9 \pm 7.4$ & $28.8 \pm 10.1$ & 0.945 \\
\hline Heart rate (bpm) & $77.3 \pm 8.9$ & $80.6 \pm 13.8$ & 0.163 \\
\hline Systolic blood pressure (mmHg) & $129.2 \pm 15.6$ & $134.5 \pm 15.2$ & 0.094 \\
\hline Diastolic blood pressure $(\mathrm{mmHg})$ & $77.8 \pm 6.5$ & $76.8 \pm 7.7$ & 0.487 \\
\hline $\mathrm{Hb}(\mathrm{mg} / \mathrm{dl})$ & $12.2 \pm 1.8$ & $12.4 \pm 1.6$ & 0.865 \\
\hline Creatinine $(\mathrm{mg} / \mathrm{dl})$ & $0.79 \pm 0.18$ & $0.88 \pm 0.27$ & 0.056 \\
\hline Uric acid (mg/dl) & $4.8 \pm 1.7$ & $4.5 \pm 1.9$ & 0.479 \\
\hline BNP & $544.5 \pm 1044$ & $601.3 \pm 1138$ & 0.797 \\
\hline LDL & $106.5 \pm 32.2$ & $137.0 \pm 48.0$ & $<0.001$ \\
\hline $\mathrm{HDL}$ & $43.9 \pm 12.4$ & $41.6 \pm 8.3$ & 0.284 \\
\hline CRP & $7.8 \pm 11.9$ & $5.2 \pm 8.1$ & 0.201 \\
\hline $\mathrm{Na}$ & $139.2 \pm 3.2$ & $138.1 \pm 3.3$ & 0.114 \\
\hline K & $4.2 \pm 0.4$ & $4.3 \pm 0.4$ & 0.092 \\
\hline $\mathrm{Ca}(\mathrm{mg} / \mathrm{dL})$ & $8.3 \pm 1.9$ & $9.0 \pm 0.9$ & 0.045 \\
\hline $\mathrm{Mg}$ & $1.9 \pm 0.7$ & $2.0 \pm 0.6$ & 0.522 \\
\hline $\mathrm{HbA1c}$ & $3.5 \pm 3.5$ & $2.4 \pm 3.5$ & 0.134 \\
\hline Albumin (gr/dl) & $2.9 \pm 0.2$ & $3.1 \pm 0.2$ & 0.338 \\
\hline Ejection fraction (\%) & $56.2 \pm 10.0$ & $53.0 \pm 12.4$ & 0.114 \\
\hline ASA (\%) & 67.3 & 86.0 & 0.034 \\
\hline Clopidogrel (\%) & 18.4 & 32.0 & 0.165 \\
\hline ASA+clopidogrel (\%) & 14.3 & 30.0 & 0.090 \\
\hline Ticagrelor (\%) & 2.0 & 10.0 & 0.204 \\
\hline Beta blocker (\%) & 46.9 & 62.0 & 0.160 \\
\hline ACEl or ARB (\%) & 77.6 & 50.0 & 0.006 \\
\hline Statin (\%) & 32.7 & 50.0 & 0.103 \\
\hline Calcium antagonist (\%) & 32.7 & 26.0 & 0.513 \\
\hline Nitrate (\%) & 20.4 & 30.0 & 0.272 \\
\hline Revascularization (PCl or CABG) (\%) & 6.1 & 38.0 & $<0.001$ \\
\hline CAD-specific index score & $2.95 \pm 2.1$ & $10.2 \pm 2.7$ & 0.027 \\
\hline Gensini score & $23.73 \pm 13$ & $71.42 \pm 21$ & $<0.001$ \\
\hline
\end{tabular}

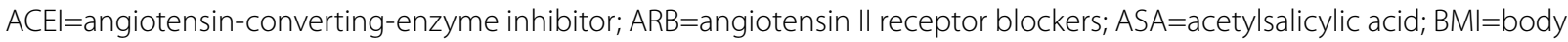
mass index; $B N P=B$-type natriuretic peptide; $C a=$ calcium; $C A B G=$ coronary artery bypass grafting; $C A D=$ coronary artery disease; $\mathrm{COPD}=$ chronic obstructive pulmonary disease; $\mathrm{CRP}=\mathrm{C}$-reactive protein; $\mathrm{Hb}=$ hemoglobin; $\mathrm{HbA} 1 \mathrm{c}=$ glycated hemoglobin; $\mathrm{HDL}=$ high-density lipoprotein; $\mathrm{K}=$ potassium; $\mathrm{LDL}=\mathrm{low}$-density lipoprotein; $\mathrm{Mg}=$ magnesium; $\mathrm{Na=sodium;} \mathrm{PCl}=$ percutaneous coronary intervention 
Table 2. Comparison of the the baseline characteristics, laboratory, and frailty score according to the end points.

\begin{tabular}{|c|c|c|c|c|c|c|}
\hline & \multicolumn{3}{|c|}{ MACE } & \multicolumn{3}{|c|}{ Death } \\
\hline & Present & Absent & $P$-value & Present & Absent & $P$-value \\
\hline Gender (\%) (female/male) & $40.0 / 60.0$ & $22.7 / 77.3$ & 0.077 & $46.2 / 53.8$ & $30.2 / 69.8$ & 0.340 \\
\hline Age (year) & $76.9 \pm 9.0$ & $75.5 \pm 8.2$ & 0.457 & $76.2 \pm 9.8$ & $76.3 \pm 8.5$ & 0.967 \\
\hline Hypertension (\%) & 65.5 & 77.3 & 0.199 & 84.6 & 68.6 & 0.335 \\
\hline Diabetes mellitus (\%) & 50.9 & 27.3 & 0.017 & 53.8 & 38.4 & 0.289 \\
\hline Current smoking (\%) & 34.5 & 27.3 & 0.438 & 61.5 & 26.7 & 0.021 \\
\hline CABG history (\%) & 18.2 & 15.9 & 0.766 & 30.8 & 15.1 & 0.229 \\
\hline COPD (\%) & 14.5 & 20.5 & 0.439 & 15.5 & 17.4 & 1.000 \\
\hline Chronic renal disease (\%) & 3.6 & 6.8 & 0.653 & 15.4 & 3.5 & 0.127 \\
\hline Stroke history (\%) & 10.9 & 6.8 & 0.727 & 15.2 & 8.1 & 0.336 \\
\hline Malignancy history (\%) & 10.9 & 0 & 0.032 & 7.7 & 5.8 & 0.580 \\
\hline $\operatorname{BMI}\left(\mathrm{kg} / \mathrm{m}^{2}\right)$ & $30.3 \pm 10.0$ & $27.0 \pm 6.6$ & 0.069 & $26.0 \pm 5.4$ & $27.6 \pm 6.1$ & 0.677 \\
\hline Heart rate (bpm) & $79.0 \pm 13.1$ & $79.0 \pm 9.6$ & 0.985 & $77.5 \pm 18.6$ & $79.2 \pm 10.3$ & 0.752 \\
\hline Systolic blood pressure $(\mathrm{mmHg})$ & $136.8 \pm 13.6$ & $125.7 \pm 15.6$ & $<0.001$ & $133.2 \pm 16.0$ & $131.7 \pm 15.5$ & 0.748 \\
\hline $\begin{array}{l}\text { Diastolic blood pressure } \\
(\mathrm{mmHg})\end{array}$ & $77.6 \pm 7.8$ & $76.8 \pm 6.0$ & 0.554 & $77.3 \pm 8.8$ & $77.2 \pm 6.8$ & 0.994 \\
\hline $\mathrm{Hb}(\mathrm{mg} / \mathrm{dl})$ & $12.3 \pm 1.9$ & $12.4 \pm 1.7$ & 0.879 & $11.6 \pm 1.9$ & $12.4 \pm 1.6$ & 0.280 \\
\hline Creatinine (mg/dl) & $0.8 \pm 0.2$ & $0.8 \pm 0.2$ & 0.341 & $0.78 \pm 0.2$ & $0.84 \pm 0.2$ & 0.347 \\
\hline Uric acid (mg/dl) & $7.1 \pm 1.9$ & $6.7 \pm 1.7$ & 0.401 & $7.2 \pm 1.7$ & $6.7 \pm 1.7$ & 0.455 \\
\hline $\mathrm{BNP}(\mathrm{pg} / \mathrm{mL})$ & $575.4 \pm 1074$ & $570.3 \pm 1116$ & 0.982 & $442.0 \pm 930.5$ & $593.0 \pm 1113.0$ & 0.983 \\
\hline $\mathrm{LDL}(\mathrm{mg} / \mathrm{dl})$ & $136.8 \pm 46.2$ & $103.2 \pm 31.6$ & $<0.001$ & $122.0 \pm 45.7$ & $121.8 \pm 43.5$ & 0.989 \\
\hline $\mathrm{HDL}(\mathrm{mg} / \mathrm{dl})$ & $41.8 \pm 8.8$ & $43.8 \pm 12.3$ & 0.353 & $43.08 \pm 9.9$ & $42.7 \pm 10.7$ & 0.909 \\
\hline $\mathrm{CRP}(\mathrm{mg} / \mathrm{L})$ & $6.1 \pm 9.0$ & $6.8 \pm 11.6$ & 0.750 & $4.4 \pm 4.4$ & $10.8 \pm 6.7$ & 0.697 \\
\hline $\mathrm{Na}(\mathrm{mEq} / \mathrm{L})$ & $138.8 \pm 3.5$ & $138.4 \pm 2.9$ & 0.574 & $139.0 \pm 3.4$ & $138.5 \pm 3.2$ & 0.606 \\
\hline $\mathrm{K}(\mathrm{mEq} / \mathrm{L})$ & $4.3 \pm 0.4$ & $4.1 \pm 0.4$ & 0.003 & $4.2 \pm 0.4$ & $4.2 \pm 0.5$ & 0.854 \\
\hline $\mathrm{Ca}(\mathrm{mg} / \mathrm{dL})$ & $8.6 \pm 1.3$ & $8.6 \pm 1.8$ & 0.896 & $9.1 \pm 0.7$ & $8.6 \pm 1.6$ & 0.252 \\
\hline $\mathrm{Mg}(\mathrm{mEq} / \mathrm{L})$ & $1.9 \pm 0.7$ & $2.0 \pm 0.6$ & 0.594 & $2.1 \pm 0.4$ & $1.9 \pm 0.7$ & 0.224 \\
\hline $\mathrm{HbA} 1 \mathrm{c}(\% \mathrm{mmol} / \mathrm{mol})$ & $2.3 \pm 3.5$ & $3.6 \pm 3.3$ & 0.080 & $3.0 \pm 1.9$ & $3.6 \pm 3.1$ & 0.351 \\
\hline Albumin (gr/dl) & $3.3 \pm 0.6$ & $3.7 \pm 0.5$ & 0.014 & $3.1 \pm 0.7$ & $3.7 \pm 0.5$ & 0.014 \\
\hline Ejection fraction (\%) & $52.2 \pm 11.9$ & $57.0 \pm 10.2$ & 0.035 & $52.8 \pm 10.6$ & $54.6 \pm 11.6$ & 0.612 \\
\hline ASA (\%) & 81.8 & 70.5 & 0.183 & 92.3 & 74.4 & 0.289 \\
\hline Clopidogrel (\%) & 27.3 & 22.7 & 0.605 & 38.2 & 23.3 & 0.304 \\
\hline ASA+clopidogrel (\%) & 25.5 & 18.2 & 0.387 & 38.5 & 19.8 & 0.156 \\
\hline Ticagrelor (\%) & 7.3 & 4.5 & 0.690 & 7.7 & 5.8 & 0.580 \\
\hline Beta blocker (\%) & 52.3 & 46.0 & 0.653 & 54.6 & 47.5 & 0.314 \\
\hline ACEI or ARB (\%) & 56.4 & 72.7 & 0.093 & 46.2 & 66.3 & 0.217 \\
\hline
\end{tabular}




\begin{tabular}{l|c|c|c|c|c|c}
\hline Statin (\%) & 56.3 & 43.5 & 0.266 & 59.5 & 47.2 & 0.322 \\
\hline Calcium antagonist (\%) & 21.8 & 38.6 & 0.078 & 15.4 & 31.4 & 0.335 \\
\hline Nitrate (\%) & 32.7 & 15.9 & 0.066 & 23.1 & 25.6 & 1.000 \\
\hline Frailty score (CSHA) & $5.2 \pm 1.5$ & $3.6 \pm 1.2$ & $<0.001$ & $5.5 \pm 1.3$ & $4.4 \pm 1.7$ & 0.026 \\
\hline CAD-specific index score & $7.3 \pm 2.5$ & $3.1 \pm 2.8$ & $<0.001$ & $6.5 \pm 2.3$ & $5.4 \pm 3.5$ & 0.161 \\
\hline Gensini score & $66.4 \pm 38.5$ & $24.4 \pm 22.1$ & $<0.001$ & $74.9 \pm 35.9$ & $43.7 \pm 37.2$ & 0.006 \\
\hline
\end{tabular}

$A C E I=$ angiotensin-converting enzyme inhibitor; $A R B=$ angiotensin $\|$ receptor blockers; $A S A=$ acetylsalicylic acid; $B M I=b o d y$ mass index; $B N P=B$-type natriuretic peptide; $C a=$ calcium; $C A B G=$ coronary artery bypass grafting; $C A D=$ coronary artery disease; $\mathrm{COPD}=$ chronic obstructive pulmonary disease; $\mathrm{CRP}=\mathrm{C}$-reactive protein; $\mathrm{CSHA}=$ Canadian Study of Health and Aging; $\mathrm{Hb}=$ hemoglobin; $\mathrm{HbA1c=glycated} \mathrm{hemoglobin;} \mathrm{HDL=high-density} \mathrm{lipoprotein;} \mathrm{K=potassium;} \mathrm{LDL=low-density} \mathrm{lipoprotein;} \mathrm{MACE=Major} \mathrm{Adverse}$ Cardiac Events; Mg=magnesium; $\mathrm{Na}=$ sodium

three restenosis, seven $\mathrm{Ml}, 17$ events of re-hospitalization, 10 major bleedings, and five events of a stroke. The effect of frailty on MACE can be seen based on the crude HR, which was 3.48 (95\% Cl 1.91-6.33). In the non-frail group, 15 patients had MACE, whereas in the frail group, 40 patients experienced MACE. Patients who experienced MACE also had high systolic blood pressure and potassium levels $(136.8 \pm 13.6 \mathrm{vs} .125 .7 \pm 15.6 \mathrm{mmHg}$, $P<0.001 ; 4.3 \pm 0.4$ vs. $4.1 \pm 0.4 \mathrm{mEq} / \mathrm{L}, P=0.003$, respectively). The frequency of diabetes mellitus, malignancy history, LDL levels, and the CAD-specific index score were found to be significantly higher only in the group with MACE (diabetes mellitus: 50.9\% vs.

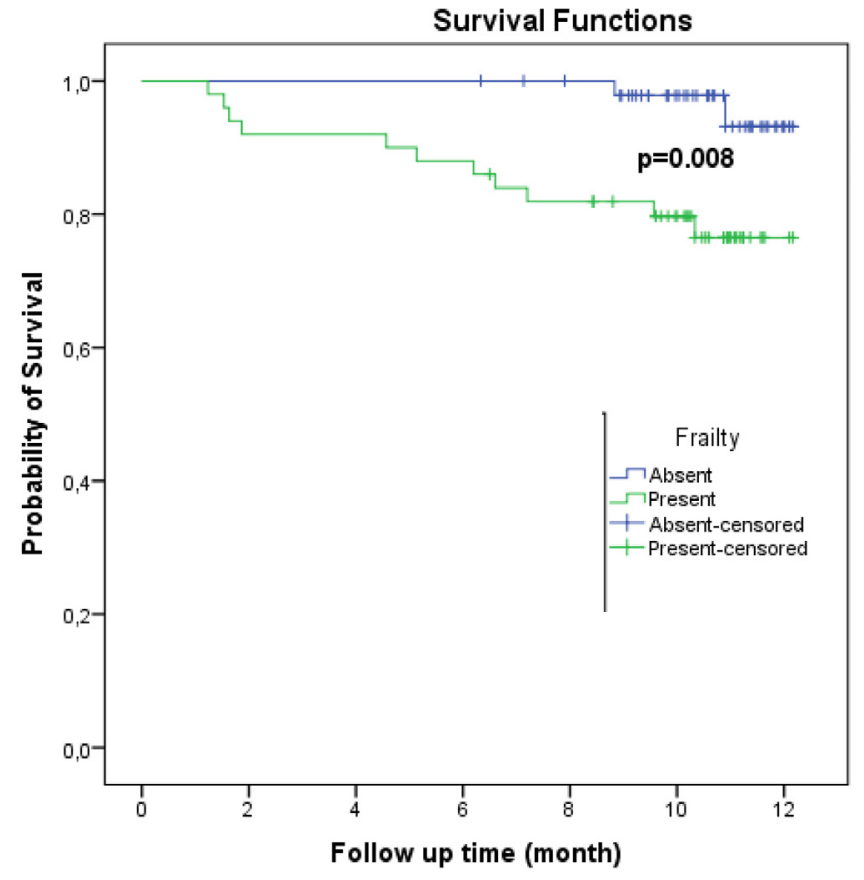

Fig. 1 - Kaplan-Meier survival curves for the frailty. Survival probabilities and their 95\% confidence intervals in the time "12 months" are 0.93 (0.83-1.00) for non-frail patients and 0.77 (0.640.90) for frail patients.
$27.3 \%, P=0.017$; malignancy history: $10.9 \%$ vs. $0 \%, P=0.032$; LDL levels: $136.8 \pm 46.2$ vs. $103.2 \pm 31.6 \mathrm{mg} / \mathrm{dl}, P<0.001$; CAD-specific index score: $7.3 \pm 2.5$ vs. $3.1 \pm 2.8, P<0.001$ ) (Table 2). The KaplanMeier test showed significant results $(P<0.001$, log-rank test, Figure 2). Based on the results, frail patients also experienced MACE earlier than non-frail patients (9.5 months $95 \% \mathrm{Cl}$ 8.7-10.3 vs. 11.3 months $95 \% \mathrm{Cl} 10.9-11.7$ ).

When the association between the frailty score and CAD-specific index score was examined, a weak correlation between these parameters was found $(k a p p a=0.311)$. When the association between the frailty score and Gensini score was

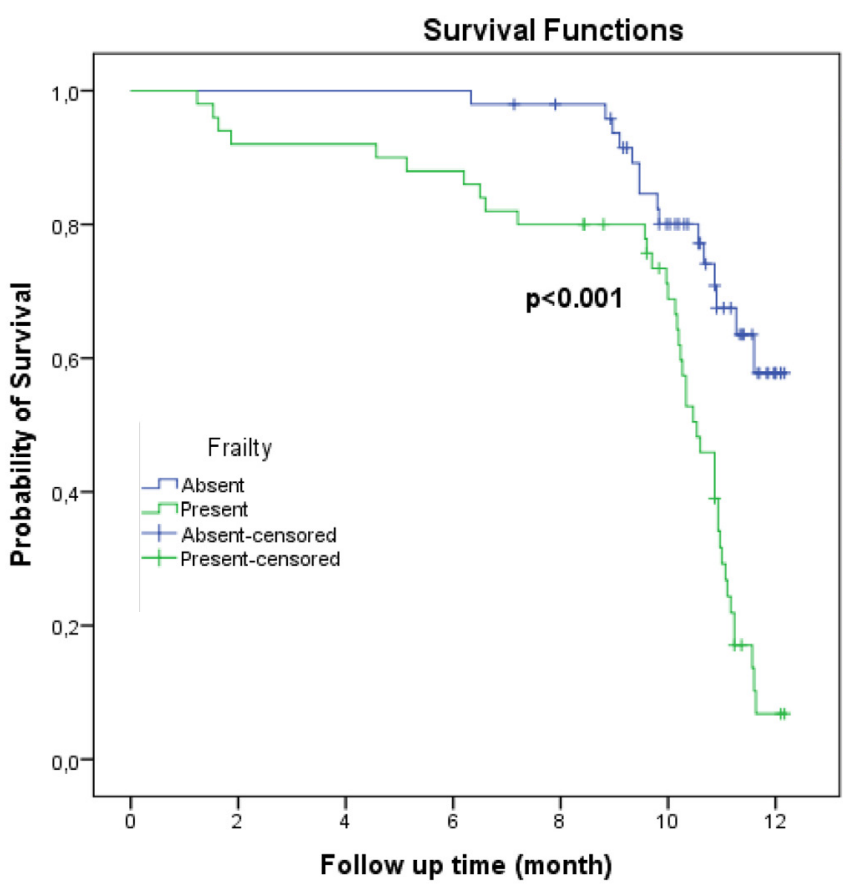

Fig. 2 - Kaplan-Meier curves of freedom from Major Adverse Cardiac Events (MACE) to one year. MACE probabilities and their 95\% confidence intervals in the time "12 months" are 0.58 (0.40-0.76) for non-frail patients and 0.07 (0.00-0.15) for frail patients. 
Table 3. Comparison of the major prognostic parameters according to the end points by multiple logistic regression analysis.

\begin{tabular}{|c|c|c|c|c|}
\hline \multirow{2}{*}{ MACE } & \multirow{2}{*}{$P$-value } & \multirow{2}{*}{ RR } & \multicolumn{2}{|c|}{$95 \% \mathrm{Cl}$ for RR } \\
\hline & & & Lower & Upper \\
\hline Albumin & 0.006 & 0.91 & 0.84 & 0.97 \\
\hline Frailty $(\mathrm{CSHA})$ - present & 0.001 & 22.94 & 3.33 & 158.19 \\
\hline CAD-specific index score $\geq 4$ & $<0.001$ & 151.58 & 15.18 & 1513.39 \\
\hline Age $\geq 80$ years & 0.044 & 7.57 & 1.06 & 53.99 \\
\hline Gensini score $\geq 20$ & 0.487 & 0.52 & 0.08 & 3.29 \\
\hline$E F<40$ & 0.726 & 1.39 & 0.22 & 8.61 \\
\hline \multirow{2}{*}{ Death } & \multirow{2}{*}{$P$-value } & \multirow{2}{*}{$\mathbf{R R}$} & \multicolumn{2}{|c|}{$95 \% \mathrm{Cl}$ for RR } \\
\hline & & & Lower & Upper \\
\hline Smoking (current) & 0.019 & 4.68 & 1.29 & 16.93 \\
\hline Frailty $(\mathrm{CSHA})-$ present & 0.016 & 7.41 & 1.44 & 38.03 \\
\hline Age $\geq 80$ years & 0.550 & 0.67 & 0.18 & 2.53 \\
\hline
\end{tabular}

$\mathrm{CAD}=$ coronary artery disease; $\mathrm{Cl}=$ confidence interval; $\mathrm{CSHA}=$ Canadian Study of Health and Aging; $E F=$ Ejection fraction; MACE=Major Adverse Cardiac Events; RR=relative risk

observed, a high correlation between these parameters was found (kappa $=0.697$ ).

When we compared the aforementioned risk factors by a multivariate analysis, a higher CAD-specific index score was associated with a significantly higher risk for MACE (RR $=151.58$, 95\% Cl 15.18-1513.39, P<0.001) (Table 3). A higher CSHA frailty score was associated with an increase in both MACE and death $(R R=22.94,95 \%$ Cl 3.33-158.19, $P=0.001$, for $M A C E ; R R=7.41$, $95 \% \mathrm{Cl} 1.44-38.03, P=0.016$, for death). A low albumin level was significantly associated with MACE for the mid-term follow-up $(\mathrm{RR}=0.91,95 \% \mathrm{Cl}$ 0.84-0.97, $P=0.006)$. Ages $>80$ years were significantly associated with MACE for the mid-term follow-up $(\mathrm{RR}=7.57,95 \% \mathrm{Cl} 1.06-53.99, P=0.044)$. A current smoking habit was significantly associated with death for the mid-term followup $(R R=4.68,95 \%$ Cl 1.29-16.93, $P=0.019)$. High Gensini score and reduced EF $(<40 \%)$ were not associated with MACE $(P=0.487$ and $P=0.726$, respectively). No other factor was associated with the composite outcome in the adjusted analysis.

\section{DISCUSSION}

In this study, frailty was one of the most potent risk predictors of MACE and death in CCS patients. Our prospective cohort study addresses the importance of classifying elderly CCS patients according to their frailty status to predict the development of essential health outcomes during a mid-term follow-up. In our study, $50.5 \%$ of the patients were frail, frailty was related to all-cause mortality, and $22.0 \%$ of frail patients experienced cardiovascular death over the 12 months of follow-up. To our knowledge, this is the first study demonstrating frailty as a risk factor for adverse midterm clinical outcomes for stable elderly CAD patients.
Along with the increase of society's life expectancy, the number of critically ill elderly patients has been increasing ${ }^{[18]}$. Frailty carries a relative morbidity and mortality risk of $>2$ across a spectrum of ACS, CCS, and transcatheter or surgical interventions ${ }^{[6]}$. Our findings are valuable because frailty may reflect the age-related heterogeneity of older populations better than chronological age alone.

It is worth noting that in our study, a high risk in the CADspecific index was associated with a higher risk for MACE in CCS patients in an adjusted analysis with the use of multiple regression. Concerning the burden of comorbidity in our study, $62.6 \%$ of the patients had high CAD-specific index scores. This represents a higher proportion than in recent studies using the same index ${ }^{[13,19]}$ We believe this may be because our study included more elderly patients than those recent studies. Frailty and CVD share common risk factors (i.e., insulin resistance, inflammation, increased age, etc. $)^{[20]}$. When the relationship between frailty and CVD is examined, there is significant evidence that the presence of one condition can accelerate or worsen the development of the other. Frail patients with CVD, especially those undergoing invasive methods such as $\mathrm{PCl}$, are more likely to have more adverse effects than people without frailty ${ }^{[21]}$. Therefore, identifying patients at an earlier stage, such as those with frailty, for preventive interventions can break this vicious cycle ${ }^{[22]}$.

Gensini scores involve an analysis of both the percentage of stenosis and the coronary artery morphology, which is associated with long-term cardiovascular outcomes ${ }^{[14,23]}$. In our study, frail patients had a higher Gensini score and although patients who experienced MACE also had high Gensini score, this score was not associated with MACE in the multivariate analysis. 
There were 13 deaths in this study, and the mortality rate in the 12 -month period was $13.1 \%$. We did not observe any deaths in the first 30 days. Gharacholou SM et al. ${ }^{[24]}$ have assessed the incidence of death in patients aged 65 years over 35 months. They have found a $12 \%$ mortality rate. Upon further analysis, they have also revealed that during a three-year follow-up, frail patients had a four-fold increased risk of death. In a Canadian study by Heyland DK et al. ${ }^{[25]}$, a lower index on a frailty scale was independently associated with an improved survival rate for a 12-month period. We also showed frailty to be strongly associated with mortality in CCS patients. These results are compatible with the evidence demonstrating the prognostic role of frailty. Our findings demonstrate the feasibility of using the CSHA in the elderly CCS patient population. We also believe this simple-to-use clinical frailty scale should be a component for the risk evaluation of elderly CCS patients.

In our study, we found a relationship between MACE and low albumin and $\mathrm{K}$ levels. The inflammation and frailty relationship is complicated, as they both linearly increase with age. Frail patients are exposed to a higher presence of factors, such as disability and medical conditions, that are potent to increase the inflammatory processes. Inflammation is known for its key role in the oxidation of lipoproteins and activation of plaques in $\mathrm{CVD}^{[8]}$. Studies have shown that levels of albumin have inverse associations with elevated molecular and cellular inflammatory agents. In frailty, inflammation stimulates a catabolic process that helps redistribute amino acids from skeletal muscles to vital organs, which results in less amino acids available for repair and maintenance functions ${ }^{[10]}$.

In our study, we found an association between MACE and malignancy history. In the literature, the prevalence of frailty in older malignant patients is high. Routine assessments of frailty in older malignant patients may have a role in guiding the treatment. In our study, patients with malignant tumors (six patients) were also included. These patients were always excluded in previous studies. Therefore, our study is closer to the experiences in the real world. Failure to detect frailty potentially exposes older cancer patients to treatments from which they might not benefit and may be harmed. Moreover, as many as $82.0 \%$ of the frail patients manifested one or more severe comorbid conditions (e.g., severe anemia, severe renal insufficiency, malignant tumor, or severe dementia). Many of these conditions are considered potential contraindications to invasive treatments. Randomized clinical studies with very few exclusion criteria are needed to study the benefits of interventions for frail CVD patients in the future.

\section{Limitations}

There were some limitations to this study. Although it is a prospective study, our results came from a single center with a relatively small number of patients. The study did not have enough statistical power to properly analyze how frailty influences the mid-term benefit of coronary angiography and the possible invasive treatment that can follow. Therefore, larger studies would help examine the relationship between frailty and clinical outcomes. We did not have a control group, and we have no long-term survival outcome data in our study. Our study was performed with CCS patients chosen for revascularization by treating physicians. The assessment of frailty was only done at baseline and was not repeated later to assess change. Also, the chosen way of measuring frailty is subjective and may have higher inter-rater variability than more objective measures of frailty. This study was not designed to make recommendations about routine frailty screening.

\section{CONCLUSION}

In conclusion, our study indicates frailty is strongly associated with a risk for mid-term outcomes for elderly CCS patients. Frailty was found to be associated with increased mortality. It is essential to identify clinically related measures of biological age and their contribution to risk when the population in question is the high number of elderly patients with CAD.

\section{No financial support. \\ No conflict of interest.}

\section{Authors' roles \& responsibilities}

CO Agreement to be accountable for all aspects of the work in ensuring that questions related to the accuracy or integrity of any part of the work are appropriately investigated and resolved; final approval of the version to be published

AD Drafting the work or revising it critically for important intellectual content; final approval of the version to be published

IG Substantial contributions to the conception or design of the work; or the acquisition, analysis, or interpretation of data for the work; final approval of the version to be published

IU Agreement to be accountable for all aspects of the work in ensuring that questions related to the accuracy or integrity of any part of the work are appropriately investigated and resolved; final approval of the version to be published

AIC Final approval of the version to be published

CEC Drafting the work or revising it critically for important intellectual content; final approval of the version to be published

OSD Agreement to be accountable for all aspects of the work in ensuring that questions related to the accuracy or integrity of any part of the work are appropriately investigated and resolved; final approval of the version to be published

MD Final approval of the version to be published

MK Substantial contributions to the conception or design of the work; or the acquisition, analysis, or interpretation of data for the work; final approval of the version to be published

AU Drafting the work or revising it critically for important intellectual content; final approval of the version to be published 


\section{REFERENCES}

1. World Health Organization. Cardiovascular Disease (CVDs) Fact Sheet [Internet]. 2017 [cited 2017 May 17]: Available from: https://www.who.int/ news-room/fact-sheets/detail/cardiovascular-diseases-(cvds).

2. Nicholson C, Gordon AL, Tinker A. Changing the way "we" view and talk about frailty.... Age Ageing. 2017;46(3):349-51. doi:10.1093/ageing/afw224.

3. Rockwood K, Fox RA, Stolee P, Robertson D, Beattie BL. Frailty in elderly people: an evolving concept. CMAJ. 1994;150(4):489-95.

4. Tse G, Gong M, Nunez J, Sanchis J, Li G, Ali-Hasan-Al-Saegh S, et al. Frailty and mortality outcomes after percutaneous coronary intervention: a systematic review and meta-analysis. J Am Med Dir Assoc. 2017;18(12):1097.e1-1097. e10. doi:10.1016/j.jamda.2017.09.002.

5. Go AS, Mozaffarian D, Roger VL, Benjamin EJ, Berry JD, Borden WB, et al. Heart disease and stroke statistics--2013 update: a report from the American heart association. Circulation. 2013;127(1):e6-e245. Erratum in: Circulation. 2013;127(1). Erratum in: Circulation. $2013 ; 127(23): e 841$. doi:10.1161/CIR.0b013e31828124ad.

6. Afilalo J, Alexander KP, Mack MJ, Maurer MS, Green P, Allen LA, et al. Frailty assessment in the cardiovascular care of older adults. J Am Coll Cardiol. 2014;63(8):747-62. doi:10.1016/j.jacc.2013.09.070.

7. Piggott DA, Varadhan R, Mehta SH, Brown TT, Li H, Walston JD, et al. Frailty, inflammation, and mortality among persons aging with HIV infection and injection drug use. J Gerontol A Biol Sci Med Sci. 2015;70(12):1542-7. doi:10.1093/gerona/glv107.

8. Wu MY, Li CJ, Hou MF, Chu PY. New insights into the role of inflammation in the pathogenesis of atherosclerosis. Int J Mol Sci. 2017;18(10):2034. doi:10.3390/ijms18102034.

9. Fried LP, Xue QL, Cappola AR, Ferrucci L, Chaves P, Varadhan R, et al. Nonlinear multisystem physiological dysregulation associated with frailty in older women: implications for etiology and treatment. J Gerontol A Biol Sci Med Sci. 2009;64(10):1049-57. doi:10.1093/gerona/glp076.

10. Chevalier S, Gougeon R, Nayar K, Morais JA. Frailty amplifies the effects of aging on protein metabolism: role of protein intake. Am J Clin Nutr. 2003;78(3):422-9. doi:10.1093/ajcn/78.3.422.

11. Rodgers JL, Jones J, Bolleddu SI, Vanthenapalli S, Rodgers LE, Shah K, et al. Cardiovascular risks associated with gender and aging. J Cardiovasc Dev Dis. 2019;6(2):19. doi:10.3390/jcdd6020019.

12. Rockwood K, Song X, MacKnight C, Bergman H, Hogan DB, McDowell I, et al. A global clinical measure of fitness and frailty in elderly people. CMAJ. 2005;173(5):489-95. doi:10.1503/cmaj.050051.

13. Sachdev M, Sun JL, Tsiatis AA, Nelson CL, Mark DB, Jollis JG. The prognostic importance of comorbidity for mortality in patients with stable coronary artery disease. J Am Coll Cardiol. 2004;43(4):576-82. doi:10.1016/j.jacc.2003.10.031.
14. Gensini GG. A more meaningful scoring system for determining the severity of coronary heart disease. Am J Cardiol. 1983;51(3):606. doi:10.1016/s00029149(83)80105-2.

15. Oishi Y, Wakatsuki T, Nishikado A, Oki T, Ito S. Circulating adhesion molecules and severity of coronary atherosclerosis. Coron Artery Dis. 2000;11(1):77-81. doi:10.1097/00019501-200002000-00013.

16. Kastrati A, Neumann FJ, Mehilli J, Byrne RA, lijima R, Büttner HJ, et al. Bivalirudin versus unfractionated heparin during percutaneous coronary intervention. N Engl J Med. 2008;359(7):688-96. Erratum in: N Engl J Med. 2008;359(9):983. doi:10.1056/NEJMoa0802944.

17. The Swedish National Board of Health and Welfare. Swedish national guidelines for stroke care 2005 [Internet]. Available from: http://www. socialstyrelsen.se/guidelines/national. [cited 2020 May 18]; 2009.

18. Martin-Loeches I, Guia MC, Vallecoccia MS, Suarez D, Ibarz M, Irazabal M, et al. Correction to: Risk factors for mortality in elderly and very elderly critically ill patients with sepsis: a prospective, observational, multicenter cohort study. Ann Intensive Care. 2019;9(1):36. Erratum for: Ann Intensive Care. 2019;9(1):26. doi:10.1186/s13613-019-0508-9.

19. Singh M, Rihal CS, Roger VL, Lennon RJ, Spertus J, Jahangir A, et al. Comorbid conditions and outcomes after percutaneous coronary intervention. Heart. 2008;94(11):1424-8. doi:10.1136/hrt.2007.126649.

20. Sergi G, Veronese N, Fontana L, De Rui M, Bolzetta F, Zambon S, et al. Pre-frailty and risk of cardiovascular disease in elderly men and women: the pro.V.A. study. J Am Coll Cardiol. 2015;65(10):976-83. doi:10.1016/j.jacc.2014.12.040.

21. Damluji AA, Huang J, Bandeen-Roche K, Forman DE, Gerstenblith G, Moscucci $M$, et al. Frailty among older adults with acute myocardial infarction and outcomes from percutaneous coronary interventions. J Am Heart Assoc. 2019;8(17):e013686. doi:10.1161/JAHA.119.013686.

22. Flint K. Which came first, the frailty or the heart disease?: exploring the vicious cycle. J Am Coll Cardiol. 2015;65(10):984-6. doi:10.1016/j.jacc.2014.12.042.

23. Niccoli G, Giubilato S, Di Vito L, Leo A, Cosentino N, Pitocco D, et al. Severity of coronary atherosclerosis in patients with a first acute coronary event: a diabetes paradox. Eur Heart J. 2013;34(10):729-41. doi:10.1093/eurheartj/ ehs393.

24. Gharacholou SM, Roger VL, Lennon RJ, Rihal CS, Sloan JA, Spertus JA, et al. Comparison of frail patients versus nonfrail patients $\geq 65$ years of age undergoing percutaneous coronary intervention. Am J Cardiol. 2012;109(11):1569-75. doi:10.1016/j.amjcard.2012.01.384.

25. Heyland DK, Garland A, Bagshaw SM, Cook D, Rockwood K, Stelfox HT, et al. Recovery after critical illness in patients aged 80 years or older: a multi-center prospective observational cohort study. Intensive Care Med. 2015;41(11):1911-20. doi:10.1007/s00134-015-4028-2. 